Article

\title{
The Effect of Whey and Soy Protein Isolates on Cognitive Function in Older Australians with Low Vitamin $B_{12}$ : A Randomised Controlled Crossover Trial
}

\author{
Ian T. Zajac*, Danielle Herreen ${ }^{\mathbb{D}}$, Kathryn Bastiaans, Varinderpal S. Dhillon and Michael Fenech
}

Health \& Biosecurity, Commonwealth Scientific and Industrial Research Organisation (CSIRO), 5000 Adelaide, South Australia, Australia

* Correspondence: ian.zajac@csiro.au; Tel.: +61-8-8303-8875

Received: 29 November 2018; Accepted: 17 December 2018; Published: 21 December 2018

check for updates

\begin{abstract}
Whey protein isolate (WPI) is high in vitamin $B_{12}$ and folate. These and other related markers (holotranscobalamin, methylmalonic acid and homocysteine) have been linked with cognitive health. This study explored the efficacy of WPI for improving cognitive function via delivery of vitamin $B_{12}$. Moderately vitamin $B_{12}$-deficient participants aged between 45 and 75 years $(n=56)$ were recruited into this randomised controlled crossover trial. Participants ( $55 \%$ female) consumed $50 \mathrm{~g}$ whey (WPI; active) or soy protein isolate (SPI; control) for eight weeks. Following a 16-week washout phase, they consumed the alternative supplement. Consumption of WPI significantly improved active $B_{12}$ and folate status but did not result in direct improvements in cognitive function. However, there was evidence of improvement in reaction time $(p=0.02)$ and reasoning speed $(p=0.04)$ in the SPI condition for females. Additional analyses showed that changes in active $\mathrm{B}_{12}, \mathrm{HcY}$ and folate measures during WPI treatment correlated with improvements in cognitive function (all $p<0.05$ ). Results indicate that WPI itself did not result in improved cognitive function but some evidence of benefit of SPI for females was found. However, consistent with previous research, we present further evidence of a role for active $\mathrm{B}_{12}, \mathrm{HcY}$ and folate in supporting cognitive improvement in adults with low B vitamin status.
\end{abstract}

Keywords: whey protein isolate; dairy; cognitive function; cobalamin; vitamin $\mathrm{B}_{12}$

\section{Introduction}

The impact of cognitive decline in a dramatically ageing population is one of the biggest challenges of the future, given its impact on both the individual and society [1]. Not only is deterioration of cognitive functioning amongst the most feared aspects of growing old due to its ability to lower a person's quality of life, it is often accompanied by significant burden [2]. Accordingly, there is a growing need to identify practical methods of delaying cognitive decline to ensure independence in aged individuals.

Epidemiological and observational studies suggest a relationship exists between nutrient deficiencies and cognitive decline in ageing adults [3-5]. In the case of vitamin $\mathrm{B}_{12}$, low levels (together with low folate levels) are a common cause of elevated total homocysteine (HcY), which has been shown to be an independent risk factor for cognitive decline and Alzheimer's disease [6-12]. Vitamin $\mathrm{B}_{12}$ deficiency is common in older adults, with prevalence increasing substantially with age [13-18]. In the UK, three surveys reported that around 1 in 20 people aged 65-74 years and at least 1 in 10 of those aged $\geq 75$ years were deficient in vitamin $B_{12}$ [18]. Moreover, an Australian survey of 
persons aged $\geq 50$ years reported $23 \%$ of participants to have low vitamin $B_{12}$ levels, with prevalence increasing to $\sim 30 \%$ for men aged $\geq 70$ years and women $\geq 80$ years [13].

Over the past few decades, studies have produced inconsistent findings regarding vitamin $B_{12}$ and its association with cognitive impairment in older adults [12]. A recent review of prospective cohort studies [19] found no association between serum vitamin $B_{12}$ concentrations and cognitive decline. However, it was noted that the four studies that used alternate biomarkers of vitamin $B_{12}$, that is, methylmalonic acid (MMA; a marker of progressed vitamin $B_{12}$ deficiency) and holotranscobalamin (the biologically active fraction of this vitamin and hereafter referred to as active $B_{12}$ ) did find evidence of an association with cognitive status [20-23]. Moreover, these markers of vitamin $B_{12}$ deficiency appear to display a stronger relationship with cognition than serum $B_{12}[16,24-26]$.

A 10-year longitudinal cohort study of 1648 individuals [20] found that a doubling of MMA was associated with a $50 \%$ faster rate of cognitive decline, with a doubling of active $B_{12}$ associated with a $30 \%$ slower rate of decline in individuals aged over 65 years. Furthermore, a 5-year prospective study of 107 community-dwelling participants aged 61-87 years without cognitive impairment at enrolment showed that the decrease in brain volume was greatest among those with lower serum vitamin $B_{12}$ and active $\mathrm{B}_{12}$ levels and higher plasma total homocysteine (HcY) and MMA levels at baseline [27]. These results are consistent with findings by Tangney et al. [28], in which high HcY and MMA levels were associated with rate of cognitive decline, along with a decrease in total brain volume.

A recent comprehensive review of the literature on the association of dairy foods and cognitive function in older adults concluded that "low-fat dairy products, when consumed regularly as part of a balanced diet, may have a number of beneficial outcomes for neuro-cognitive health during ageing" and identified the whey fraction as being particularly rich in a range of bioactives, including proline-rich polypeptides, $\alpha$-lactalbumin and $B_{12}$, which may support brain health in diverse ways [10]. Whey is a natural by-product of the manufacture of cheese, with $100 \mathrm{~g}$ of dried powder providing $2.5 \mu \mathrm{g}$ of vitamin $\mathrm{B}_{12}$, equivalent to $100 \%$ of the Recommended Dietary Allowance (RDA). Acid whey powder contains high amounts of lactose (60-70 g per $100 \mathrm{~g})$, which is problematic given the increased risk of lactose malabsorption in older adults [29]. Whey protein isolate (WPI), on the other hand, has less than $1 \mathrm{~g}$ lactose per $100 \mathrm{~g}$ and is also richer in vitamin $\mathrm{B}_{12}(6 \mu \mathrm{g} / 100 \mathrm{~g})$. Additionally, WPI has an $80 \%$ lower level of sodium and 14-fold higher level of natural folate relative to acid whey powder. While WPI has already been shown to be beneficial for improving cognitive performance in the context of memory tasks in stress-vulnerable subjects [30], the bioavailability and bioefficacy of vitamin $\mathrm{B}_{12}$ from WPI remains relatively unexplored, particularly in relation to age-related cognitive decline.

The purpose of the present study was to consider the role that dairy-based products such as WPI may have on nutritional markers associated with age-related cognitive decline. Primary outcomes including the impact of WPI supplementation on vitamin $B_{12}$ status and related factors in individuals with subclinical $B_{12}$ levels at baseline have already been reported [31] but are briefly revisited herein. This study specifically explores the impact of WPI supplementation on cognitive function measured during the intervention. Furthermore, it explores the relationship between changes in various biomarkers of $B_{12}$ status (serum $B_{12}$, active $B_{12}$, MMA and $H c Y$ ) and changes in cognitive function during the course of the active intervention.

\section{Materials and Methods}

\subsection{Screening and Recruitment of Participants}

The study was advertised in local newspapers in the Adelaide metropolitan area and on the CSIRO clinic website. Interested participants contacted the clinic to arrange an appointment for screening. Fifty-six eligible participants attended an information session and read the study information sheet before providing written informed consent to participate in the study. Figure 1 provides an overview of screening and recruitment and Table 1 provides an overview of baseline characteristics of study completers. All data collection visits for this study occurred between September 2014 and June 2015. 
Inclusion criteria were: healthy subjects aged between 45 and 75 years, not taking vitamin $\mathrm{B}_{12}$ /choline/antioxidant vitamins at doses that exceed $25 \%$ of the Recommended Dietary Allowance, subclinical vitamin $\mathrm{B}_{12}$ deficiency as defined previously [31] (using the following parameters: serum concentration of $B_{12}$ in the range of 100-350 pmol/L, plasma MMA $>0.20 \mu \mathrm{mol} / \mathrm{L}$ and serum creatinine concentration of $120 \mu \mathrm{mol} / \mathrm{L}$ or less) and willing to consume the quantities of WPI or SPI specified for the trial.

Exclusion criteria were: cognitive deficiencies indicated by Mini Mental State Examination Score $\leq 24$, current smokers, people who habitually consume more than two standard alcoholic drinks per day, BMI $\geq 35 \mathrm{~kg} / \mathrm{m}^{2}$, diagnosed with diabetes and/or lactose intolerance, history of pernicious anaemia or atrophic gastritis and regular users of antacids.

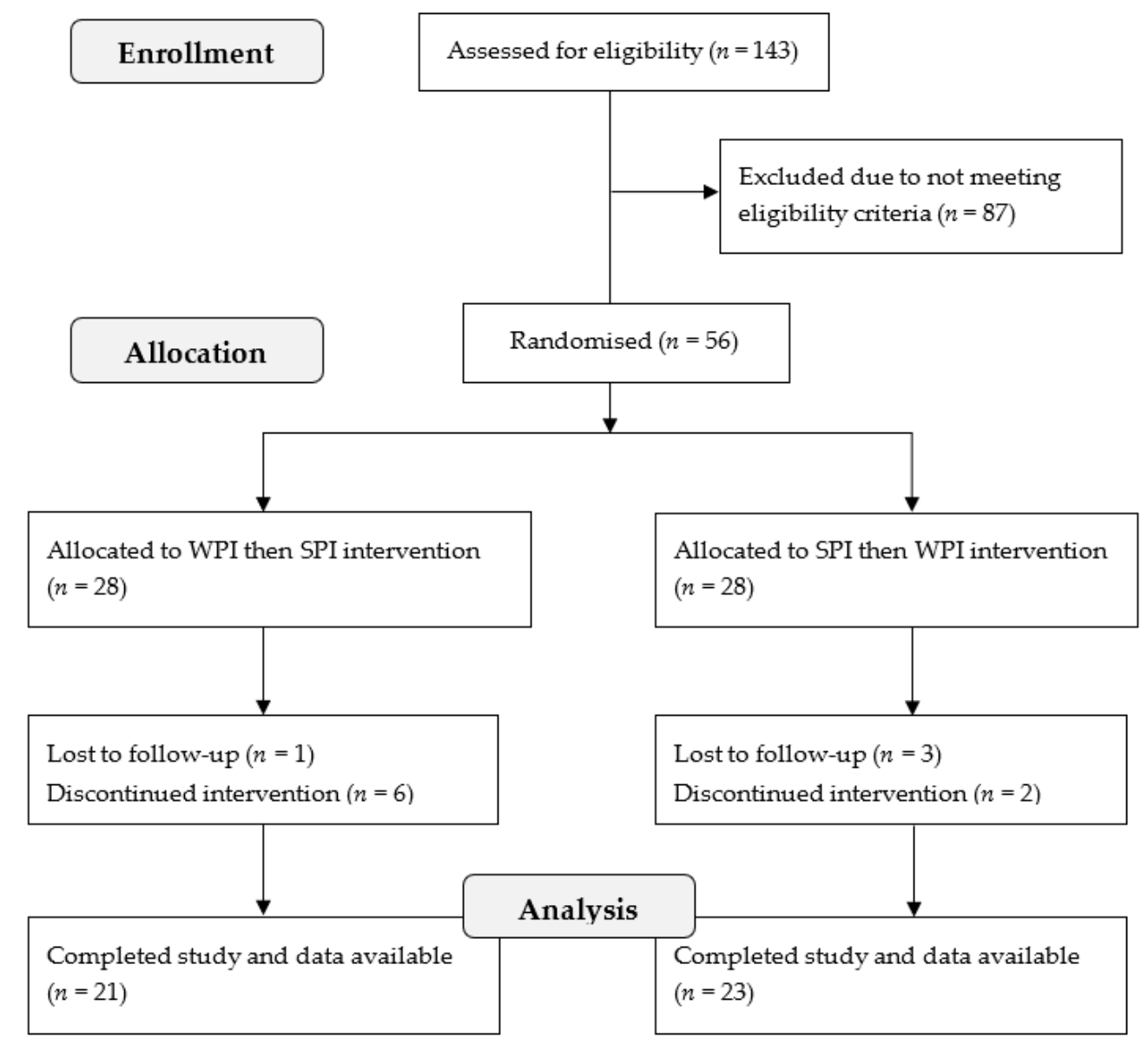

Figure 1. Consort diagram of the intervention trial.

Table 1. Baseline characteristics of participants who completed the study.

\begin{tabular}{ccc}
\hline \multirow{2}{*}{ Variable } & \multicolumn{2}{c}{ Treatment Order } \\
\cline { 2 - 3 } & $\begin{array}{c}\text { SPI then WPI } \\
(\boldsymbol{n}=\mathbf{2 3})\end{array}$ & $\begin{array}{c}\text { WPI then SPI } \\
(\boldsymbol{n}=\mathbf{2 1})\end{array}$ \\
\hline \% Female $(n)$ & $43 \%(10)$ & $52 \%(11)$ \\
Mean Age in years (SD) & $61.8(1.94)$ & $61.1(1.78)$ \\
Mean Body Mass Index (SD) & $26.8(0.76)$ & $26.41(0.88)$ \\
\hline
\end{tabular}

SPI: soy protein isolate; WPI: whey protein isolate. 


\subsection{Intervention Design}

This study was a registered (ACTRN12614000159651) randomised controlled crossover intervention, which was approved by the CSIRO Human Research Ethics Committee. Participants were randomised to daily intake of $50 \mathrm{~g}$ WPI or $50 \mathrm{~g}$ SPI (control) for eight weeks. Following an intervening 16-week washout phase, participants crossed over to the alternative supplement for the final eight weeks. The randomisation scheme was generated by the clinical trials manager using the online resource website: http:/ / www.randomization.com. Both products were packaged in matching opaque containers with a numeric allocation number to ensure blinding of participants, researchers and clinical trial staff.

Participants were asked to maintain their habitual diet during the intervention trial but refrain from eating foods high in vitamin $B_{12}$ (i.e., foods with vitamin $B_{12}$ levels $>4.9 \mu \mathrm{g} / 100 \mathrm{~g}$ ) and also refrain from taking supplements containing vitamin $\mathrm{B}_{12} /$ choline/antioxidants). Dietary restrictions included limiting consumption of vegetables or pulses ( 2 servings/day), fruits or juices ( 3 servings/day), black tea or coffee (2 cups/day), chocolate (50 g/day), wine (200 mL/day) and/or beer (375 mL/day) in order to avoid an excessive intake of antioxidants to minimise variation between subjects and groups. Participants completed 3-day food and beverage intake records at baseline and endpoint to monitor their adherence to these restrictions and were supported throughout the study by a dietitian.

The WPI or SPI was consumed daily as $25 \mathrm{~g}$ blended in $200 \mathrm{~mL}$ fruit juice or water twice a day so that the total daily intake was $50 \mathrm{~g}$ WPI or $50 \mathrm{~g}$ SPI each day. The WPI and SPI were provided in $25 \mathrm{~g}$ sachets (two per participant for each day of the intervention phases). A compliance checklist for use of the WPI and SPI sachets was completed by the participants.

During the washout period, participants were allowed to return to their habitual dietary habits and were required to avoid consumption of supplements containing vitamin $B_{12}$ or foods fortified with vitamin $B_{12}$. Serum $B_{12}$ was checked mid-way during the washout period. Those exceeding $350 \mathrm{pmol} / \mathrm{L}$ serum $\mathrm{B}_{12}$ concentration were required to restrict intake of foods rich in $\mathrm{B}_{12}$ until they achieved a $<350 \mathrm{pmol} / \mathrm{L}$ serum concentration before starting the second treatment phase.

\subsection{Nutritional Profile of WPI and SPI}

The nutritional composition of WPI and SPI is shown in Table 2. According to the manufacturer's product data, $100 \mathrm{~g}$ of WPI and SPI contributed 6 and $0 \mu \mathrm{g}$ of vitamin $\mathrm{B}_{12}$, respectively. Independent analysis by PathWest Laboratory Medicine WA (Nedlands, Western Australia, Australia) showed that WPI contained $5.64 \mu \mathrm{g}$ of vitamin $\mathrm{B}_{12}$ per $100 \mathrm{~g}$, whereas the amount of vitamin $\mathrm{B}_{12}$ in SPI was less than $0.34 \mu \mathrm{g} / 100 \mathrm{~g}$.

Table 2. Nutritional composition of WPI and SPI as per manufacturer's product specifications.

\begin{tabular}{cccc}
\hline Composition & Type & Amount in WPI & Amount in SPI \\
\hline Protein $(\%)$ & Total proteins & $93.1(\%)$ Dry basis & $91.0 \%$ Dry basis \\
& $\beta$-Lactoglobulin & $45 \%$ & - \\
& $\alpha$-Lactabumin & $15 \%$ & - \\
& GMP (glycomacropeptide) & $16 \%$ & - \\
& Minor components & $3-5 \%$ & - \\
& Immunoglobulins & $4 \%$ & - \\
& Bovine serum albumin & $1 \%$ & - \\
Fat $(\%)$ & Lactoferrin & $0.1 \%$ & $2.5 \%$ \\
& Total fats & $1 \%$ & $0.8 \%$ \\
& Saturated fats & - & $1.6 \%$ \\
& Polyunsaturated & - & $0.6 \%$ \\
& Monounsaturated & - & $0.5 \%$ \\
\hline
\end{tabular}


Table 2. Cont.

\begin{tabular}{cccc}
\hline Composition & Type & Amount in WPI & Amount in SPI \\
\hline Carbohydrate (\%) & Total carbohydrates & $1.2 \%$ & $1 \%$ \\
& Lactose & $1.2 \%$ & - \\
& Sucrose & - & $<1 \%$ \\
Vitamins (per $100 \mathrm{~g})$ & Pantothenic acid & $<1.0 \mathrm{mg}$ & - \\
& Riboflavin $\left(\mathrm{B}_{2}\right)$ & $0.32 \mathrm{mg}$ & - \\
& $\mathrm{B}_{6}$ & $0.22 \mathrm{mg}$ & $0.1 \mathrm{mg}$ \\
& Thiamine $\left(\mathrm{B}_{1}\right)$ & $0.12 \mathrm{mg}$ & - \\
& $\alpha$-Tocopherol & $<0.1 \mathrm{mg}$ & - \\
& Niacin $\left(\mathrm{B}_{3}\right)$ & $<0.01 \mathrm{mg}$ & - \\
& Folacin & $458 \mu \mathrm{g}$ & - \\
& B & $6.0 \mu \mathrm{g}$ & $0.0 \mu \mathrm{g}$ \\
& Potassium & $1005 \mathrm{mg}$ & $1300 \mathrm{mg}$ \\
& Calcium & $307 \mathrm{mg}$ & - \\
& Phosphorus & $210 \mathrm{mg}$ & - \\
& Sodium & $188 \mathrm{mg}$ & $800 \mathrm{mg}$ \\
& Chloride & $11 \mathrm{mg}$ & - \\
\hline
\end{tabular}

\subsection{Biochemical Outcome Measures}

Blood samples were collected at the beginning and end of each of the intervention phases and half-way through the washout phase, that is, at $0,8,16,24$ and 32 weeks, within the clinical research unit. Blood samples were used fresh or biobanked frozen at $-80{ }^{\circ} \mathrm{C}$ depending on the requirements of each assay. The biochemical outcome measures included in the present analyses were: serum $B_{12}$, active $B_{12}$ (holotranscobalamin), methylmalonic acid (MMA), plasma total homocysteine levels (HcY) and serum folate. Complete descriptions of these measures and associated laboratory processing and results have been described elsewhere [31].

\subsection{Tests of Cognitive Function}

The CSIRO Cognitive Assessment Battery (C-CAB) comprised of 10 individual cognitive tasks that measure cognitive domains including processing speed, reaction time/attention, reasoning speed, verbal and numeric working memory, immediate and delayed word memory. The tasks utilised obtain latency/response time and accuracy data with performance outcomes for each measure reflecting both of these components. The test battery was programmed to run in the Inquisit version 4 environment [32] and the battery took approximately 45 minutes to complete. Participants completed the C-CAB at each of their clinic visits. The tests used to measure performance on each of the cognitive domains are now described in the order completed.

\subsubsection{Immediate Word Memory}

Participants were presented with a list of 15 words obtained from the MRC Psycholinguistic Database [33], which included one-to-two syllable words with high concreteness $(\mathrm{Mean}=572.81$, $\mathrm{SD}=35.92$ ) and meaningfulness (Mean $=681.87, \mathrm{SD}=83.31$ ) ratings. Prior to presentation, participants were instructed to remember the words and were informed they will be tested immediately, as well as after approximately 20 minutes. Words were presented in the middle of the computer, one at a time, with a display time of 2-seconds and an inter-stimulus interval (ISI) of 500-millseconds (msec). Parallel word lists were used for alternate testing sessions to remove practice effects. Immediately after presentation, participants were tested using a 30 words list. The list included the original 15 words plus 15 new distractors. Words were shown one-at-a-time in the centre of the computer screen with a $500 \mathrm{msec}$ ISI between the participant's response and subsequent word stimulus. Participants indicated whether the word was from the initial word list or not, by pressing 'Yes' and 
'No' response keys. Raw outcome measures included mean response latency-time between stimulus onset and participant's response-and accuracy measures.

\subsubsection{Processing Speed}

The first task assessing processing speed was adapted from previous research [34]. A code table was presented at the top of the computer screen and comprised nine symbols arranged horizontally, to which nine digits, presented directly beneath them, were paired. For each item, one symbol was presented in the centre of the computer screen and participants responded by left clicking the mouse on its corresponding digit in a $3 \times 3$ numerical response grid positioned at the bottom of the screen. The raw outcome measure was the number of items correctly completed in $90 \mathrm{~s}$.

The second task was a computerised string search task adapted from the ETS Kit of Factor Referenced Tests [35]. In this task, participants were required to decide whether two number strings, presented side-by-side, were identical and press the 'Yes' or 'No' key on the keyboard accordingly. The raw outcome measure was the number of items completed correctly in $90 \mathrm{~s}$.

\subsubsection{Reaction Time/Attention}

Two-choice and four-choice reaction time tasks were used to measure this domain and were adapted from our previous studies [34]. To begin each trial, the participant pressed the ' $\mathrm{H}^{\prime}$ key on a response keypad. This action triggered a cue symbol (+) of approximately 40 px which appeared in the centre of the computer screen together with two or four black bordered empty target squares (100 px) positioned 150 px each side of the cue (left and right for two-choice, with addition of top and bottom square for four-choice). After a variable ISI ranging from $1000 \mathrm{msec}$ to $2500 \mathrm{msec}$, a black arrow was presented in one of the squares (arrow direction was congruent with location; pointing left, right, up or down). Participants responded by pressing the corresponding response arrow in the response keypad as quickly as possible (response keys were positioned left, right, above and below the ' $\mathrm{H}^{\prime}$ key). Practice phases required participants to complete four and eight trials correctly. Mean response latencies for each task were subsequently estimated over 30 valid trials defined as: 1) response was correct; 2) response latency was not less than $150 \mathrm{~ms}$; and 3) response latency was not greater than mean latency +3.5 times the intra-individual standard deviation of latencies obtained during the second phase of practice trials in each task.

\subsubsection{Verbal Working Memory}

This was measured using a letter memory task adapted from previous studies [36]. In this task, participants were initially instructed to memorise a set of five letters presented sequentially on the computer screen for $2000 \mathrm{msec}$ each with an ISI of $500 \mathrm{msec}$. Following a warning probe of $3000 \mathrm{msec}$, 31 test trials commenced and participants were required to indicate whether the test letter displayed was in the original learned set or not. In the second phase of this task, participants were required to remember a new set of eight letters which did not include the original five, followed by 31 test trials as per above. Raw outcome measures included mean response latency and accuracy.

\subsubsection{Numerical Working Memory}

This was measured using a number memory task adapted from previous studies [36] and was operationally equivalent to the verbal working memory task described above. However, in this task, participants were instructed to memorise sets of numbers (either five or eight) and to make yes/no decisions about numbers presented subsequently in the test phase. Raw outcome measures included mean response latency and accuracy. 


\subsubsection{Delayed Word Memory}

Approximately 20 minutes into the cognitive battery, participants were tested again on the 15 words presented at the start of the session. The test consisted of 30 trials involving the original 15 words, plus 15 new distracters not used in the immediate recognition test. All other presentation parameters and scoring parameters were as per the immediate recognition test described above.

\subsubsection{Reasoning Speed}

Two tasks adapted from the odd-man-out reaction time paradigm were used to assess this domain [37]. The tests used are more complex than simple reaction time because they assess the ability to make reasoned decisions concerning distal relationships between stimuli [38]. In the first version, trials consisted of eight circles arranged horizontally with the total stimulus set being $640 \mathrm{px}$ wide and $84 \mathrm{px}$ high. In each set, three target circles were illuminated red and two targets were closer together in relation to the third target. Participants indicated to which side-left or right-of the two closer targets the odd-man-out (i.e., third target) was located. Participants completed two practice phases consisting of six trials each. The test-phase consisted of 40 trials and raw outcome measures included mean response latency and accuracy.

The second task is procedurally equivalent to the first task. However, in this version, trials consisted of eight mixed shapes (squares, diamonds and triangles) arranged horizontally. The target stimuli were triangles as opposed to illuminated circles and participants indicated to which side-left or right—of the two closer triangles the odd-man-out (i.e., third triangle) is located. Outcomes measures were as per above.

\subsection{Sample Size, Data Processing and Analysis}

The required sample size for this study was estimated using GPower. Results showed a minimum of $n=74$ participants were required for a repeated-measures model assuming a small within-between interaction effect $\left(\eta^{2}=0.02\right)$ with $90 \%$ power. For crossover designs, as used herein, this figure is halved, requiring a minimum of $n=37$ participants. The number of recruited participants who completed this study was $n=44$, thus satisfying statistical power requirements.

Transformations were undertaken to normalise distributions of cognitive tasks for analysis purposes. In line with previous studies [39], work rates representing the number of items completed per second were calculated. Then, these work rates were adjusted for accuracy (work rate $\times \%$ correct). Finally, performance was averaged across tasks measuring the same domain (e.g., reaction time/attention) to arrive at a composite measure.

Cognitive data were analysed at the Intention-to-Treat level and therefore included all participants who commenced the trial (whether or not they withdrew). Change in cognitive function was assessed using linear mixed effects models-capable of handling missing data-and the repeated nature of the measurements were accounted for by permitting random slopes and intercepts for each participant for each treatment. Fixed effects included time, treatment and time by treatment interactions. An unstructured covariance matrix was specified for random effects and all models controlled for participant's sex, age and the order of assigned treatments. The assumption of normally distributed residuals was assessed and was satisfied for all models.

The final analyses assessed the relationship between changes in vitamin $B_{12}$ and related parameters occurring during the WPI intervention period only and corresponding changes in cognitive function using first-order correlations adjusted for sex and age covariates. The calculation of change scores was thus based only on those who attended final follow-up $(n=44)$ and who therefore had complete data. 


\section{Results}

Participants in this sample had a mean age of 60 years (SD $=8.5$ years) and were reasonably well balanced in regard to sex (55\% female). Table 3 provides average levels of cognitive performance over the course of the study as well as mean change in cognitive function for each domain. Equivalence of the groups at baseline was confirmed via no statistically significant differences between treatment arms for any measure (all $p \geq 0.42$ ). Descriptive statistics regarding changes in cognition show that it was generally neutral or positive.

Table 3. Means ( \pm standard error of the mean) for cognitive variables at baseline, endpoint and for overall change.

\begin{tabular}{cccccccc}
\hline \multirow{2}{*}{ Cognitive Domain } & \multirow{2}{*}{ Treatment } & \multicolumn{2}{c}{ Baseline } & \multicolumn{2}{c}{ Endpoint } & \multicolumn{2}{c}{ Change } \\
\cline { 3 - 7 } & & Mean & \pm SE & Mean & \pm SE & Mean & \pm SE \\
\hline \multirow{2}{*}{ Processing Speed } & WPI & 0.36 & 0.01 & 0.37 & 0.01 & 0.01 & 0.00 \\
& SPI & 0.37 & 0.01 & 0.37 & 0.01 & 0.00 & 0.00 \\
Reasoning Speed & WPI & 0.83 & 0.04 & 0.86 & 0.04 & 0.04 & 0.02 \\
Reaction & SPI & 0.79 & 0.04 & 0.88 & 0.04 & 0.09 & 0.02 \\
Time/Attention & WPI & 1.67 & 0.05 & 1.67 & 0.05 & -0.01 & 0.02 \\
Numeric Working & SPI & 1.66 & 0.05 & 1.70 & 0.05 & 0.04 & 0.02 \\
Memory & WPI & 1.14 & 0.04 & 1.22 & 0.04 & 0.07 & 0.03 \\
Verbal Working & SPI & 1.18 & 0.05 & 1.22 & 0.04 & 0.04 & 0.02 \\
Memory & WPI & 0.83 & 0.03 & 0.88 & 0.03 & 0.05 & 0.02 \\
Immediate Word & SPI & 0.85 & 0.04 & 0.91 & 0.03 & 0.06 & 0.02 \\
Memory & WPI & 0.91 & 0.04 & 0.91 & 0.04 & 0.00 & 0.03 \\
Delayed Word & SPI & 0.93 & 0.03 & 0.89 & 0.04 & -0.03 & 0.03 \\
Memory & WPI & 0.82 & 0.04 & 0.81 & 0.04 & -0.02 & 0.03 \\
& SPI & 0.78 & 0.04 & 0.81 & 0.04 & 0.03 & 0.03 \\
\hline
\end{tabular}

Analysis of data using mixed effects models showed significant overall time effects for reasoning speed, verbal working memory and numeric working memory (all $p \leq 0.001$ ). In addition, there were significant time by treatment interaction effects observed for reasoning speed $(p=0.04)$ and reaction time $(p=0.02)$. In both cases, performance increased over the duration of the intervention with a significantly greater increase observed during the SPI compared to WPI treatment. Additional three way interactions (time by treatment by sex) showed that these effects were only evident in females during SPI treatment (both $p<0.05$ ). As shown in Figure 2, there was generally no change in performance for males during either treatment for either cognitive domain but significant direct changes were observed for females during SPI treatment only.

The results of this intervention on various biochemical scores have been reported in full previously [31]. However, given the presence of prior studies suggesting a relationship between alternate markers of $\mathrm{B}_{12}$ status and cognition, additional analyses were conducted in order to examine changes in markers of $B_{12}$ status during the active WPI treatment phase only and their associations with observed changes in cognitive function during the same treatment period. Briefly, the results of the intervention on the parameters of interest are provided in Table 4 . WPI treatment lead to significant direct changes in active $B_{12}$ and serum folate, however changes in MMA did not quite reach significance. Correlations between changes in these biochemical measures and cognitive function during both WPI and SPI intervention periods can be seen in Table 5. These correlations were fully adjusted for age and sex covariates. As can be seen, 5/6 significant correlations emerged for the WPI intervention. Increases in in active $B_{12}$ were associated with improvements in processing speed. Similarly, increased serum folate was associated with improvements in delayed word memory. Reductions (i.e., improvements) in homocysteine levels were related to improvements in processing speed, numeric working memory and verbal working memory. In the SPI condition, homocysteine changes were related to reasoning speed with higher levels equating to reduced performance. 
We conducted the same analyses using combined $\mathrm{B}_{12}\left(\mathrm{cB}_{12}\right)$, a combined indicator of corrected $\mathrm{B}_{12}$ status [31] and the pattern of correlations was the same as for active $B_{12}$.

(A)

Reasoning Speed

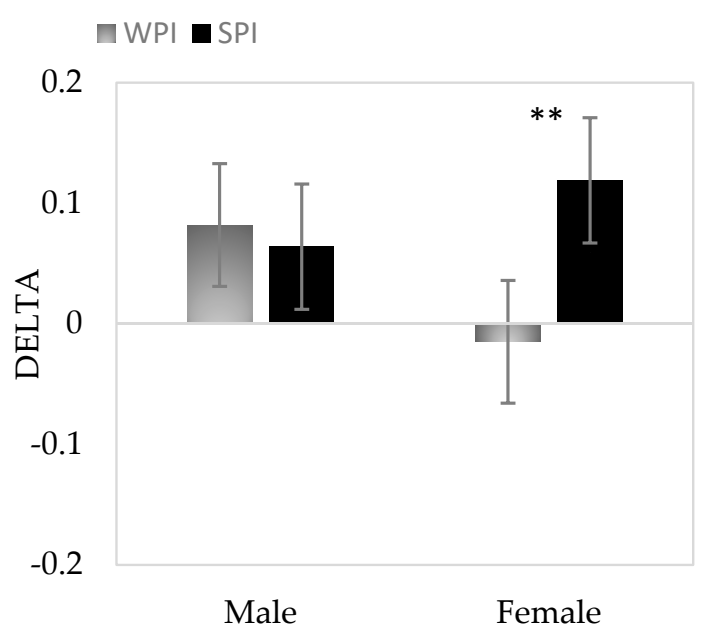

(B)

Reaction Time

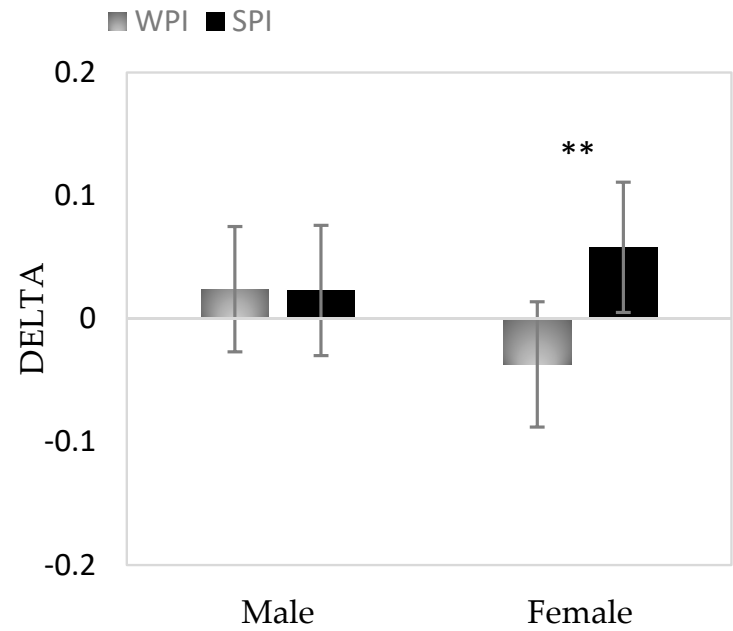

Figure 2. Mean change scores and $95 \%$ Confidence Intervals for Treatment $\times$ Gender interactions for Delta (A) Reasoning Speed and (B) Reaction Time. ${ }^{* *} p<0.01$.

Table 4. Baseline scores (Mean \pm SE) and percentage change observed due to treatment.

\begin{tabular}{cccccc}
\hline & \multicolumn{2}{c}{ SPI } & \multicolumn{2}{c}{ WPI } & \multirow{2}{*}{ p-Value $^{\mathbf{a}}$} \\
\cline { 1 - 5 } & Baseline & \% Change & Baseline & \% Change & \\
\hline Serum B $_{12}(\mathrm{pmol} / \mathrm{L})$ & $261.7 \pm 8.45$ & $\downarrow-9.47$ & $260.2 \pm 10.59$ & $\downarrow-4.05$ & 0.14 \\
Active B $_{12}(\mathrm{pmol} / \mathrm{L})$ & $70.16 \pm 3.97$ & $\downarrow-2.21$ & $68.7 \pm 4.13$ & $\uparrow+19.08$ & $<0.001$ \\
MMA (mol/L) & $0.26 \pm 0.021$ & $\uparrow+12.24$ & $0.26 \pm 0.022$ & $\downarrow-3.96$ & 0.09 \\
tHcy (mol/L) & $11.98 \pm 0.53$ & $\uparrow+3.09$ & $11.89 \pm 0.55$ & $\downarrow-1.78$ & 0.14 \\
Serum folate (nmol/L) & $34.78 \pm 0.26$ & $\downarrow-1.05$ & $34.45 \pm 1.79$ & $\uparrow+12.92$ & $<0.01$ \\
\hline
\end{tabular}

a Comparison of percentage change between treatments. $\uparrow$ Increase, $\downarrow$ decrease.

Table 5. Correlations between changes in biometric measures and changes in cognitive function during each treatment period; adjusted for sex and age covariates.

\begin{tabular}{|c|c|c|c|c|c|c|}
\hline & & $\Delta$ Serum $B_{12}$ & $\Delta$ Active $B_{12}$ & $\Delta$ MMA & $\Delta$ tHcy & $\Delta$ Serum Folate \\
\hline \multirow{2}{*}{$\Delta$ Processing Speed } & WPI & 0.09 & $0.29 *$ & -0.03 & $-0.33 *$ & 0.22 \\
\hline & SPI & 0.24 & 0.06 & -0.01 & 0.17 & 0.12 \\
\hline \multirow{2}{*}{$\Delta$ Reasoning Speed } & WPI & -0.03 & 0.01 & -0.11 & 0.21 & -0.10 \\
\hline & SPI & 0.22 & 0.18 & -0.01 & $-0.49 * *$ & 0.09 \\
\hline \multirow{2}{*}{$\Delta$ Numeric Working Memory } & WPI & 0.00 & 0.00 & 0.18 & $-0.31 *$ & 0.03 \\
\hline & SPI & 0.07 & 0.11 & -0.11 & 0.03 & -0.04 \\
\hline \multirow{2}{*}{$\Delta$ Verbal Working Memory } & WPI & 0.01 & 0.10 & 0.04 & -0.24 & -0.10 \\
\hline & SPI & -0.20 & -0.05 & 0.21 & 0.23 & 0.05 \\
\hline \multirow{2}{*}{$\Delta$ Reaction Time/Attention } & WPI & 0.03 & 0.13 & -0.08 & -0.20 & $0.25 *$ \\
\hline & SPI & -0.09 & -0.03 & -0.03 & -0.06 & -0.16 \\
\hline \multirow{2}{*}{$\Delta$ Immediate Word Memory } & WPI & 0.11 & 0.07 & -0.11 & -0.23 & 0.15 \\
\hline & SPI & 0.15 & 0.18 & -0.02 & 0.24 & -0.14 \\
\hline \multirow{2}{*}{$\Delta$ Delayed Word Memory } & WPI & 0.03 & -0.02 & 0.03 & -0.06 & $0.39 * *$ \\
\hline & SPI & 0.03 & 0.05 & -0.15 & -0.03 & 0.12 \\
\hline
\end{tabular}




\section{Discussion}

This study sought to examine the effects of WPI and SPI on cognitive function and vitamin $B_{12}$ status in low $\mathrm{B}_{12}$ individuals. Cognitive function was measured for a variety of important domains using a robust cognitive assessment battery. Overall, there were no effects of WPI on cognitive function, which generally remained stable across visits during this treatment. On the contrary, SPI appeared to have benefits for the cognitive domains of reasoning speed and reaction time in females only. Given the age of participants in this sample (45-75 years) and the presence of this effect true for females only, this finding possibly reflects the impact of soy isoflavones on cognitive function in post-menopausal women [40]. A recent meta-analysis concluded that soy isoflavones exert a positive effect on a broad range of cognitive abilities in females and that this effect is robust in women as young as 60 years [41].

Despite the absence of a main treatment effect for WPI in terms of its ability to improve cognitive performance, positive findings were evident regarding changes in biometric measures of vitamin $B_{12}$ status during WPI treatment and changes in cognitive function. Specifically, increases in active $B_{12}$ and serum folate were associated with corresponding improvements in some cognitive domains. Reductions in homocysteine levels were also consistently related to improvements in cognitive performance, including working memory. Whilst there were no clear treatment effects linking WPI specifically to improved cognitive function, the changes observed in these key biochemical markers and the relation of these to improved cognition were consistent with the broader research literature regarding the role of $\mathrm{B}_{12}$, folate and homocysteine in helping to maintain good cognitive function [12].

The finding of direct associations between changes in biochemical and cognitive measures despite the absence of any effect directly attributable to WPI likely reflects the choice of the control treatment. More specifically, although SPI is a useful comparison given its different nutritional profile to WPI in terms of levels of B-vitamins and folate, the isoflavones present can have an impact on cognitive function, most notably in females [40]. Therefore, both treatments were arguably 'active' in relation to their ability to affect cognitive performance and the absence of any interaction effect favouring WPI does not preclude potential benefits of this for improving cognition as a result of its demonstrated influence on vitamin B-status. Thus, future studies will need to consider their choice of control treatment more carefully if the primary outcome concerns cognitive function.

In addition to using a relatively active control treatment, this study employed a relatively short intervention duration (eight weeks). Prior research has proposed that interventions involving otherwise healthy participants, as used herein, require durations as long as 2-to-5 years in order to demonstrate an impact on cognitive function [42]. Thus, it has been suggested that such studies might benefit from recruiting individuals at-risk of enhanced rates of cognitive decline. Given the relationships observed herein between changes in $B_{12}$ related markers and improved cognitive performance, future studies should consider the potential for dairy-based supplements to slow the rate of decline in individuals with quantifiable Age-Associated Memory Impairment (AAMI). These individuals are particularly interesting given the absence of underlying pathology (e.g., dementia) explaining their decline and the fact that they do not yet meet criteria for MCI [43].

The potential utility of using WPI or SPI for extended periods of time as a means of supplementing diets must be balanced against any potential negative impacts of these. For example, dairy (WPI) has been linked with self-reported gut discomfort and subsequent avoidance of such products [44]. Question marks also remain in relation to soy and its potential impact on endocrinology [45], as well as the presence of contaminants such as aluminium in soy products [46].

In conclusion, although this intervention did not demonstrate a direct effect of WPI supplementation on cognitive function, the results provide some support to the notion of vitamin $B_{12}$ and folate status having a role in supporting cognitive health. Specifically, important vitamin $B_{12}$ and folate related markers were improved as a result of WPI supplementation and these changes were correlated with improvements in cognitive performance. However, the findings from this study are limited to similarly aged adults with subclinical vitamin $B_{12}$ deficiency and further research is needed to explore how these findings may relate to other groups and populations. 
Author Contributions: Conceptualisation, I.T.Z., V.S.D. and M.F.; Formal analysis, I.T.Z., D.H. and K.B.; Methodology, I.T.Z.; Project administration, I.T.Z., K.B. and V.S.D.; Supervision, I.T.Z.; Writing-original draft, I.T.Z., D.H. and K.B.; Writing-review \& editing, D.H., V.S.D. and M.D. All authors read and approved the final manuscript.

Funding: This research was funded by the Dairy Research Institute, USA (National Dairy Council).

Acknowledgments: We thank Anne McGuffin (Clinical Trials Manager) and Lindy Lawson (Clinical Nurse) for their role in the planning and collection of samples and other data during the intervention trial.

Conflicts of Interest: The authors declare no conflict of interest.

\section{References}

1. Williams, K.N.; Kemper, S. Interventions to Reduce Cognitive Decline in Aging. J. Psychosoc. Nurs. Ment. Health Serv. 2010, 48, 42-51. [CrossRef] [PubMed]

2. Salthouse, T.A. What and when of cognitive aging. Curr. Dir. Psychol. Sci. 2004, 13, 140-144. [CrossRef]

3. Ogawa, S. Nutritional management of older adults with cognitive decline and dementia. Geriatr. Gerontol. Int. 2014, 14 (Suppl. 2), 17-22. [CrossRef] [PubMed]

4. Morris, M.C. Nutritional determinants of cognitive aging and dementia. Proc. Nutr. Soc. 2012, 71, 1-13. [CrossRef] [PubMed]

5. Solfrizzi, V.; Panza, F.; Frisardi, V.; Seripa, D.; Logroscino, G.; Imbimbo, B.P.; Pilotto, A. Diet and Alzheimer's disease risk factors or prevention: The current evidence. Expert Rev. Neurother. 2011, 11, 677-708. [CrossRef] [PubMed]

6. Duthie, S.J.; Whalley, L.J.; Collins, A.R.; Leaper, S.; Berger, K.; Deary, I.J. Homocysteine, B vitamin status, and cognitive function in the elderly. Am. J. Clin. Nutr. 2002, 75, 908-913. [CrossRef]

7. Riggs, K.M.; Spiro, A., 3rd; Tucker, K.; Rush, D. Relations of vitamin B-12, vitamin B-6, folate, and homocysteine to cognitive performance in the Normative Aging Study. Am. J. Clin. Nutr. 1996, 63, 306-314. [CrossRef] [PubMed]

8. Jensen, E.; Dehlin, O.; Erfurth, E.M.; Hagberg, B.; Samuelsson, G.; Svensson, T.; Hultberg, B. Plasma homocysteine in 80-year-olds: Relationships to medical, psychological and social variables. Arch. Gerontol. Geriatr. 1998, 26, 215-226. [CrossRef]

9. Refsum, H.; Nurk, E.; Smith, A.D.; Ueland, P.M.; Gjesdal, C.G.; Bjelland, I.; Tverdal, A.; Tell, G.S.; Nygard, O.; Vollset, S.E. The Hordaland Homocysteine Study: A community-based study of homocysteine, its determinants, and associations with disease. J. Nutr. 2006, 136, 1731S-1740S. [CrossRef]

10. Camfield, D.A.; Owen, L.; Scholey, A.B.; Pipingas, A.; Stough, C. Dairy constituents and neurocognitive health in ageing. Br. J. Nutr. 2011, 106, 159-174. [CrossRef]

11. McCracken, C.; Hudson, P.; Ellis, R.; McCaddon, A.; Medical Research Council Cognitive Function and Ageing Study. Methylmalonic acid and cognitive function in the Medical Research Council Cognitive Function and Ageing Study. Am. J. Clin. Nutr. 2006, 84, 1406-1411. [PubMed]

12. Vogel, T.; Dali-Youcef, N.; Kaltenbach, G.; Andrès, E. Homocysteine, vitamin B12, folate and cognitive functions: A systematic and critical review of the literature. Int. J. Clin. Pract. 2009, 63, 1061-1067. [CrossRef] [PubMed]

13. Flood, V.M.; Smith, W.T.; Webb, K.L.; Rochtchina, E.; Anderson, V.E.; Mitchell, P. Prevalence of low serum folate and vitamin B12 in an older Australian population. Aust. N. Z. J. Public Health 2006, 30, 38-41. [CrossRef] [PubMed]

14. Mirkazemi, C.; Peterson, G.M.; Tenni, P.C.; Jackson, S.L. Vitamin B12 deficiency in Australian residential aged care facilities. J. Nutr. Health Aging 2012, 16, 277-280. [CrossRef] [PubMed]

15. Van Asselt, D.Z.; de Groot, L.C.; van Staveren, W.A.; Blom, H.J.; Wevers, R.A.; Biemond, I.; Hoefnagels, W.H. Role of cobalamin intake and atrophic gastritis in mild cobalamin deficiency in older Dutch subjects. Am. J. Clin. Nutr. 1998, 68, 328-334. [CrossRef]

16. Lindenbaum, J.; Rosenberg, I.H.; Wilson, P.W.; Stabler, S.P.; Allen, R.H. Prevalence of cobalamin deficiency in the Framingham elderly population. Am. J. Clin. Nutr. 1994, 60, 2-11. [CrossRef] [PubMed]

17. Green, T.J.; Venn, B.J.; Skeaff, C.M.; Williams, S.M. Serum vitamin B12 concentrations and atrophic gastritis in older New Zealanders. Eur. J. Clin. Nutr. 2005, 59, 205-210. [CrossRef] 
18. Clarke, R.; Grimley Evans, J.; Schneede, J.; Nexo, E.; Bates, C.; Fletcher, A.; Prentice, A.; Johnston, C.; Ueland, P.M.; Refsum, H.; et al. Vitamin B12 and folate deficiency in later life. Age Ageing 2004, 33, $34-41$. [CrossRef]

19. O'Leary, F.; Allman-Farinelli, M.; Samman, S. Vitamin B(1)(2) status, cognitive decline and dementia: A systematic review of prospective cohort studies. Br. J. Nutr. 2012, 108, 1948-1961. [CrossRef]

20. Clarke, R.; Birks, J.; Nexo, E.; Ueland, P.M.; Schneede, J.; Scott, J.; Molloy, A.; Evans, J.G. Low vitamin B-12 status and risk of cognitive decline in older adults. Am. J. Clin. Nutr. 2007, 86, 1384-1391. [CrossRef]

21. Tangney, C.C.; Tang, Y.; Evans, D.A.; Morris, M.C. Biochemical indicators of vitamin B12 and folate insufficiency and cognitive decline. Neurology 2009, 72, 361-367. [CrossRef]

22. Hooshmand, B.; Solomon, A.; Kareholt, I.; Leiviska, J.; Rusanen, M.; Ahtiluoto, S.; Winblad, B.; Laatikainen, T.; Soininen, H.; Kivipelto, M. Homocysteine and holotranscobalamin and the risk of Alzheimer disease: A longitudinal study. Neurology 2010, 75, 1408-1414. [CrossRef]

23. Kivipelto, M.; Annerbo, S.; Hultdin, J.; Bäckman, L.; Viitanen, M.; Fratiglioni, L.; Lökk, J. Homocysteine and holo-transcobalamin and the risk of dementia and Alzheimers disease: A prospective study. Eur. J. Neurol. 2009, 16, 808-813. [CrossRef]

24. Clarke, R.; Sherliker, P.; Hin, H.; Nexo, E.; Hvas, A.M.; Schneede, J.; Birks, J.; Ueland, P.M.; Emmens, K.; Scott, J.M.; et al. Detection of vitamin B12 deficiency in older people by measuring vitamin B12 or the active fraction of vitamin B12, holotranscobalamin. Clin. Chem. 2007, 53, 963-970. [CrossRef] [PubMed]

25. Miller, J.W.; Garrod, M.G.; Rockwood, A.L.; Kushnir, M.M.; Allen, L.H.; Haan, M.N.; Green, R. Measurement of total vitamin B12 and holotranscobalamin, singly and in combination, in screening for metabolic vitamin B12 deficiency. Clin. Chem. 2006, 52, 278-285. [CrossRef] [PubMed]

26. Hin, H.; Clarke, R.; Sherliker, P.; Atoyebi, W.; Emmens, K.; Birks, J.; Schneede, J.; Ueland, P.M.; Nexo, E.; Scott, J.; et al. Clinical relevance of low serum vitamin B12 concentrations in older people: The Banbury B12 study. Age Ageing 2006, 35, 416-422. [CrossRef] [PubMed]

27. Vogiatzoglou, A.; Refsum, H.; Johnston, C.; Smith, S.M.; Bradley, K.M.; de Jager, C.; Budge, M.M.; Smith, A.D. Vitamin B12 status and rate of brain volume loss in community-dwelling elderly. Neurology 2008, 71, 826-832. [CrossRef]

28. Tangney, C.C.; Aggarwal, N.T.; Li, H.; Wilson, R.S.; Decarli, C.; Evans, D.A.; Morris, M.C. Vitamin B12, cognition, and brain MRI measures: A cross-sectional examination. Neurology 2011, 77, 1276-1282. [CrossRef]

29. Levitt, M.; Wilt, T.; Shaukat, A. Clinical implications of lactose malabsorption versus lactose intolerance. J. Clin. Gastroenterol. 2013, 47, 471-480. [CrossRef]

30. Markus, C.R.; Olivier, B.; de Haan, E.H. Whey protein rich in alpha-lactalbumin increases the ratio of plasma tryptophan to the sum of the other large neutral amino acids and improves cognitive performance in stress-vulnerable subjects. Am. J. Clin. Nutr. 2002, 75, 1051-1056. [CrossRef]

31. Dhillon, V.S.; Zabaras, D.; Almond, T.; Cavuoto, P.; James-Martin, G.; Fenech, M. Whey protein isolate improves vitamin B12 and folate status in elderly Australians with subclinical deficiency of vitamin B12. Mol. Nutr. Food Res. 2017, 61, 1600915. [CrossRef] [PubMed]

32. Inquisit 4 Computer Software; Millisecond Software: Seattle, WA, USA, 2015.

33. Wilson, M. Mrc Psycholinguistic Database-Machine-Usable Dictionary, Version 2.00. Behav. Res. Meththods Instrum. Comput. 1988, 20, 6-10. [CrossRef]

34. Zajac, I.T.; Burns, N.R.; Nettelbeck, T. Do Purpose-Designed Auditory Tasks Measure General Speediness? Int. J. Intell. Sci. 2012, 2, 23-31. [CrossRef]

35. Ekstrom, R.B.; French, J.W.; Harman, H.H.; Derman, D. Kit of Factor-Referenced Cognitive Tests; Educational Testing Service: Princeton, NJ, USA, 1976.

36. Scholey, A.; Ossoukhova, A.; Owen, L.; Ibarra, A.; Pipingas, A.; He, K.; Roller, M.; Stough, C. Effects of American ginseng (Panax quinquefolius) on neurocognitive function: An acute, randomised, double-blind, placebo-controlled, crossover study. Psychopharmacology 2010, 212, 345-356. [CrossRef] [PubMed]

37. Jensen, A.R. Reaction time and psycyometric g. In A Model for Intelligence; Eysenck, H.J., Ed.; Springer: Berlin, Germany, 1982; pp. 93-132.

38. Diascro, M.N.; Brody, N. Odd-Man-out and Intelligence. Intelligence 1994, 19, 79-92. [CrossRef]

39. Danthiir, V.; Wilhelm, O.; Schulze, R.; Roberts, R.D. Factor structure and validity of paper-and-pencil measures of mental speed: Evidence for a higher-order model? Intelligence 2005, 33, 491-514. [CrossRef] 
40. Kritz-Silverstein, D.; Von Muhlen, D.; Barrett-Connor, E.; Mathias, B. Isoflavones and cognitive function in older women: The SOy and Postmenopausal Health in AGing (SOPHIA) Study. Menopause 2003, 10, 196-202. [CrossRef] [PubMed]

41. Cheng, P.-F.; Chen, J.-J.; Zhou, X.-Y.; Ren, Y.-F.; Huang, W.; Zhou, J.-J.; Xie, P. Do soy isoflavones improve cognitive function in postmenopausal women? A meta-analysis. Menopause 2015, 22, 198-206. [CrossRef] [PubMed]

42. Smith, A.D.; Smith, S.M.; de Jager, C.A.; Whitbread, P.; Johnston, C.; Agacinski, G.; Oulhaj, A.; Bradley, K.M.; Jacoby, R.; Refsum, H. Homocysteine-Lowering by B Vitamins Slows the Rate of Accelerated Brain Atrophy in Mild Cognitive Impairment: A Randomized Controlled Trial. PLoS ONE 2010, 5, e12244. [CrossRef] [PubMed]

43. Lee, G.; Elashoff, D.; Di, L.; Teng, E.; Melchor, S.; Kim, J.; Lu, P.-H. Age-associated memory impairment increases risk of conversion to MCI and dementia. Alzheimer's Dement. 2012, 8, P544. [CrossRef]

44. Yantcheva, B.; Golley, S.; Topping, D.; Mohr, P. Food avoidance in an Australian adult population sample: The case of dairy products. Public Health Nutr. 2016, 19, 1616-1623. [CrossRef] [PubMed]

45. Jargin, S.V. Soy and phytoestrogens: Possible side effects. Germ. Med. Sci. 2014, 12. [CrossRef]

46. Chuchu, N.; Patel, B.; Sebastian, B.; Exley, C. The aluminium content of infant formulas remains too high. BMC Pediatr. 2013, 13, 162. [CrossRef] [PubMed]

(C) 2018 by the authors. Licensee MDPI, Basel, Switzerland. This article is an open access article distributed under the terms and conditions of the Creative Commons Attribution (CC BY) license (http:/ / creativecommons.org/licenses/by/4.0/). 